Regul at $i$ on of drug transporter s by PDZ adapt or prot ei ns and nucl ear recept or $s$

\begin{tabular}{|l|l|}
\hline 著者 & Kat o Yuki o, Wat anabe Chi zur u, Tsuj i Aki ra \\
\hline $\begin{array}{l}\mathrm{j} \text { our nal or } \\
\text { publ i cat i on ti t l e }\end{array}$ & Eur opean Journal of Phar naceut i cal Sci ences \\
\hline vol une & 27 \\
\hline number & 5 \\
\hline page r ange & $487-500$ \\
\hline year & $2006-0401$ \\
\hline URL & ht t p: //hdl . handl e. net /2297/3639 \\
\hline
\end{tabular}




\title{
Regulation of drug transporters by PDZ adaptor proteins and nuclear receptors
}

\author{
Yukio Kato \\ Chizuru Watanabe \\ Akira Tsuji
}

Division of Pharmaceutical Sciences, Graduate School of Natural Science and Technology, Kanazawa University, Kanazawa, Ishikawa 920-1192, Japan 
Running title:

Molecular mechanisms involved in transporter regulation

Corresponding author:

Prof. Akira Tsuji, ph.D

Division of Pharmaceutical Sciences, Graduate School of Natural Science and

Technology, Kanazawa University, Kakuma, Kanazawa, Ishikawa 920-1192, Japan

Tel:(81)-76-234-4479/Fax:(81)-76-264-6284

E-mail: tsuji@kenroku.kanazawa-u.ac.jp

Document statistics:

number of text pages: 50

number of tables: 3

number of figures: 3

Key words:

Transporter; membrane transport; PDZ domain; protein interaction; SLC superfamily 


\section{ABSTRACT}

Drug transporters have been suggested to be involved in various aspects of pharmacokinetics ldentification and characterization of drug transporters have given us a scientific basis for understanding drug disposition, as well as the molecular mechanisms of drug interaction and inter-individual/inter-species differences. On the other hand, regulatory mechanisms of drug transporters are still poorly understood, and information is limited to induction and down-regulation of drug transporters by various microsomal enzyme inducers. Little is known about the molecular machinery that directly interacts with the drug transporters. As a first step to clarify such molecular mechanisms, recent studies have identified PDZ (PSD-95/Discs-large/ZO-1) domain-containing proteins that directly interact with the so-called PDZ binding motif located at the C-terminus of drug transporters. Some of the PDZ proteins have been suggested to regulate transporters via at least two pathways, i.e., stabilization at the cell-surface and direct modulation of transporter function. Therefore, it is possible that membrane transport of therapeutic agents is not only governed by the drug transporters themselves, but also indirectly by PDZ proteins. The PDZ proteins are classified as a family, the members of which are thought to have distinct, but also redundant physiological roles. The purpose of this review article is to summarize the available knowledge on protein interactions and functional modulation of drug transporters. 


\section{Overview}

\section{1-1) Introduction}

Recent progress in molecular biology has led to the identification of various types of drug transporters which accept therapeutic agents as substrates. Drug transporters are generally classified into the SLC (solute carrier) and ABC (ATP-binding cassette) superfamilies. These drug transporters are believed to be directly involved in arious aspects of drug absorption, distribution and excretion of drugs (Sai and Tsuji 2004; Shitara et al., 2004; Marzolini et al., 2004; Hagenbuch and Meier 2003; Jonker and Schinkel 2004). However, little is yet known about how these transporters are organized in the plasma membranes, and how their expression and function are regulated. Protein-protein interaction is involved in many biological events, including signal transduction, intracellular trafficking, scaffold formation for protein networks, cellular polarization and protein turnover. In this review article, therefore, we summarize recent findings on direct interaction of drug transporters with so-called adaptor proteins that contain PDZ (PSD-95/Discs-large/ZO-1) domains in their structures (Gisler et al., 2003; Anzai et al., 2004; Kato et al., 2004, 2005) and discuss the physiological roles of these PDZ domain containing proteins, including their expression, localization and effect on membrane transporters. Finally, we review the available information on peroxisome proliferator-activated receptor (PPAR)- $\alpha$ as a transcriptional 
factor that affects gene expression of both drug transporters and PDZ proteins.

\section{1-2) Significance of identifying protein-transporter interactions}

An understanding of protein-protein interactions involving drug transporters would have various advantages. Firstly, it would help to elucidate the molecular machinery that ensures vectorial transport of nutrients and xenobiotics. Epithelial cells, especially in kidney and small intestine, play fundamental roles in the overall absorption of neutrients, and in the secretion of xenobiotics and metabolites (Fig. 1). It is well established that transporters play fundamental roles in such vectorial transport. In renal proximal tubules of rodents, for example, both organic cation transporter (OCT) 1 and OCT2 are localized on basolateral membranes and are involved in uptake of organic cations from circulating blood, whereas organic cation/carnitine transporter (OCTN) 1 and OCTN2 are localized on apical membranes and are proposed to be involved in renal secretion of those compounds into the urine (Jonker and Schinkel 2004; Wright 2005; Ohashi et al., 2001; Tamai et al., 2004) (Fig. 1). These OCT/OCTN family members recognize various types of organic cations as substrates (Jonker and Schinkel 2004; Wright 2005; Tamai et al., 2000) (Fig. 1). OCTN2 and OCTN1 are also involved in reabsorption of carnitine from the tubular duct space (Nezu et al., 1999; Tamai et al., 1998, 2000) 
(Fig. 1). To obtain such vectorial transport of xenobiotics and nutrients (Fig. 1), OCT/OCTN family members should be appropriately targeted to either basolateral or apical plasma membranes (Fig. 1).

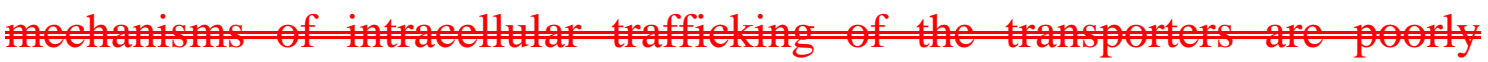
mderste Protein-protein interaction research may=thus throw light on intrinsic mechanisms governing drug absorption and secretion by clarifying intracellular trafficking mechanisms of the transporters.

Certain types of therapeutic agents can also be recognized by the nutrient transporters in the small intestine. For example, $\beta$-lactam antibiotics, ACE inhibitors and bestatin are recognized by oligopeptide transporter (PEPT) 1 which is expressed on apical membranes of small intestinal absorptive epithelial cells and thought to be involved in absorption of peptides and therapeutic agents. and renal tubular epithelial (Tsuji and Tamai, 1996; Daniel 2004; Nielsen and Brodin 2003; Han and Amidon 2000). Monocarboxylate transporter (MCT) 1 expressed on apical membranes in the small intestine could also be involved in intestinal absorption of anionic compounds (Tsuji and Tamai 1996). Organic anion transporting polypeptide (OATP)-B, which recognizes estrone sulfate as an endogenous substrate, is also expressed on the apical membrane in human small intestine and transports various types of hydrophobic organic anions (Kobayashi et al., 2003; Nozawa et al., 2004). On the other hand, P-glycoprotein and multidrug resistance associated protein (MRP) 2 are 
involved in, the secretion of various types of therapeutic agents in the small intestine (Benet et al., 2004; Kunta and Sinko 2004; Sai and Tsuji 2004). 盘 the liver and kidney, numeus stulies have confimed fumetional

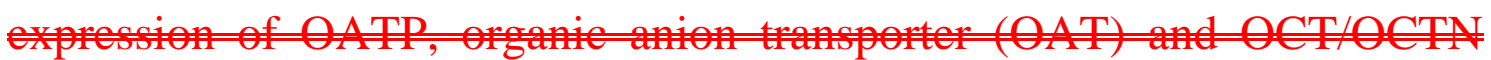
family members on basolateral and apical suffaces of hepatocytes and renal cubular epithelial cells, where they are involved in vectorial transport of numerous therapeutic agents (Sai and Tsuij 2004; Shitara et al, 2004; Ma lini al., 2004; Hag 2003; Jon and Sthinel Protein-protein interaction research may thus uncover intrinsic mechanisms governing drug absorption and secretion e.g., trafficking and retention of the transporters themselves.

Secondly, adaptor proteins which can bind to drug transporters may affect the cell-surface expression, function and/or intracellular trafficking of the transporters, thereby influencing drug disposition. Pioneering studies have indicated that PDZ (PSD-95/Discs-large/ZO-1) domain-containing proteins such as PDZK1 and $\mathrm{Na}^{+} / \mathrm{H}^{+}$exchanger regulatory factor (NHERF1, SLC9A3R1) interact with and regulate the function of cystic fibrosis transmembrane conductance regulator protein (CFTR)(Wang et al., 2000; Raghuram et al., 2001). It has also been clarified that accessory proteins such as 4F2hc and CD147 are required for functional expression of neutral amino acid transporter and monocarboxylate transporter (MCT) 1, respectively (Enerson and Drewes 
2003; Halestrap and Meredith 2004; Palacin and Kanai 2004). Since the drug transporters are transmembrane proteins whose cell-surface expression should be subject to homeostatic regulation, such regulatory factors may indirectly influence the membrane transport of substrates through interaction with the transporters.

Finally, identification of protein interactions could provide a structural basis for the interactions in networks of transporters and other proteins. In general, active transport requires a driving force, by which a substrate can be concentratively transported against an electrochemical gradient. For example, uptake of substrates by PEPT1 utilizes an inwardly directed $\mathrm{H}^{+}$gradient, which is produced by $\mathrm{Na}^{+} / \mathrm{H}^{+}$exchanger (NHE). Uptake of substrates by organic anion transporter (OAT) 1 utilizes an outwardly directed gradient of dicarboxylate which is produced by the $\mathrm{Na}^{+}$ dicarboxylate transporter (NaDC). Therefore, to obtain efficient transporting activity, the appropriate driving force should be produced in close proximity to the drug transporters to avoid diffusive loss of the ion gradient. Indeed, uptake of dipeptides by the $\mathrm{H}^{ \pm}$teligopeptide transporter on the apical membrane in Caco-2 cells has been suggested to be indirectly controlled by NHEs, which supply the $\mathrm{H}^{+}$gradient for this peptide uptake mechanism(s) (Thwaites et al., 2002). Hence, this oligopeptide transport system exhibits apparent $\mathrm{Na}^{+}$-dependence in its substrate uptake, and NHE inhibitors hinder uptake of glycylsarcosine (GlySar) in Caco-2 cells 
(Thwaites et al., 2002; Anderson et al., 2003). Functional modulation by NHE can also occur intracellularly, since NHE can export $\mathrm{H}^{+}$, which is taken up by oligopeptide transporters. Kennedy et al. (2002) suggested that optimal absorptive transport of GlySar depends on the NHE activity, and the reliance of an oligopeptide transporter upon a $\mathrm{Na}^{+}$-dependent intracellular $\mathrm{pH}$ regulatory mechanism such as NHE may partly explain the apparent $\mathrm{Na}^{+}$-dependence of high-affinity dipeptide uptake observed in PEPT2-expressing astrocytes (Kennedy et al. 2002). Transporter-adaptor interactions may provide the structural basis of functional coupling of different transporters lisaser.

\section{PDZ binding motif in drug transporters as a signal for protein interaction}

2-1) PDZ interaction motif localized on C-terminus of various drug transporters

PDZ domains are generally composed of 80-90 amino acids, and are defined as domains commonly found in postsynaptic density PSD-95/SAP90, the Drosophila septate junction protein disc-large, and the tight junction protein ZO-1 (Hung et al., 2002; Biber et al., 2004; Brone and Eggermont 2005). PDZ domains are thought to play important roles in targeting of proteins to specific cell membranes, assembling proteins into signaling complexes for efficient transduction, and regulating the function 
of transmembrane proteins (Hung et al., 2002; Biber et al., 2004; Brone and Eggermont 2005). PDZ domains bind to the PDZ binding motif usually located at the C-terminus of interacting proteins. The binding specificity of PDZ domains is critically determined by the amino acid located at the extreme C-terminus (position 0) and the amino acid at position -2 . PDZ domains are classified into three groups (class I to III) based on the amino acid sequence in the interacting motif.

Some of the drug transporters which belong to the SLC superfamily have a class I PDZ binding motif (-S/T-X- $\Phi, \Phi$ is a hydrophobic amino acid) at their extreme C-terminus (Table 1). Interestingly, most of the transporters with the class I PDZ motif in human and/or mouse orthologs, such as PEPT1, PEPT2, OAT4, OCT3, OCTN1, OCTN2, OATP-A and OATP-B, are expressed on apical membranes in kidney and/or small intestine (Table 1), implying that this motif could play a role as an apical localization signal (Russel et al., 2002). The presence of the PDZ binding motif in apically expressed drug transporters could be compatible with the idea that PDZ domain-containing proteins orchestrate plasma membrane retention and post endocytic sorting operations through interaction with membrane proteins in polarized epithelial cells (Campo et al., 2005). A fundamental role of the PDZ motif may also be supported by the fact that this motif is generally conserved between human and mouse, except for PEPT1 and OATP family members (Table 1). Further studies are 
needed to clarify whether such difference in C-terminal sequences is relevant to differential regulation of transporters in various species.

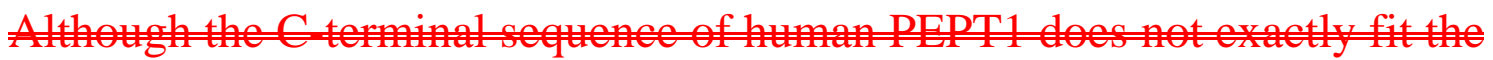

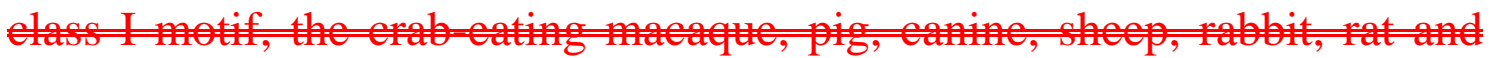
mouse orthologs all have the $G$-terminal sequence-TXM which fits a class I motif. The status of the PDZ motif in the OATP family is more eontroversial, probably because human OATP orthologs do not necessarily (1) 20 2003). In the OATP1A family, f the Oatp1a4/Oatp2, Oatp1a5/Oatp3, Oatp1a6/Oatp5) is - TKI which fits a elass I motif. In the OАTP2B family, on the other hand, OATP-B has a elass I motif (Table 1), whereas the C-terminal sequence of Oatpzb1/Oatp9 is Qिए

2-2) Requirement of C-terminal PDZ motif for intracellular localization

The presence of an apical sorting signal in the C-terminal region has been suggested for several drug transporters including MRP2. The MRP2 mutant with the last three amino acids (-TKF) deleted is predominantly localized in the basolateral membrane of MDCK cells (Harris et al., 2001). The deletion of 15 C-terminal amino acids results in impaired apical localization of MRP2 in HepG2 cells (Nies et al., 2002). 
These results suggest that the C-terminal residues are essential for apical localization of MRP2. However, the MRP2 mutant with the last three amino acids deleted is targeted to plasma membranes of L1210 cells, whereas the parent construct of MRP2 is localized intracellularly (Harris et al., 2001), suggesting that the function of the sorting signal in transporters depends on the host cell type, possibly due to differences in the adaptor proteins interacting with the sorting signal.

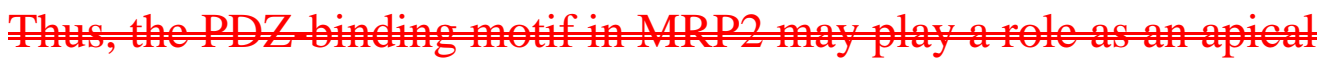

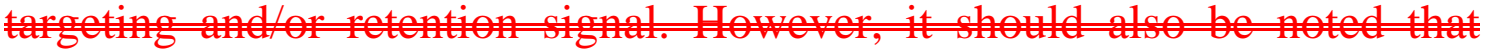
PDZ binding motifs act as a signal for targeting of at least certain types of proteins to subcellular compartments other than apical membranes. For example, basolateral sorting of ErbB receptors, potassium channel Kir 2.3 and $\gamma$-aminobutyric acid transporter BGT-1 requires a PDZ binding motif in the cytosolic domain (Campo et al., 2005). Thus, to understand better the physiological roles of the PDZ binding motif in drug transporters, the nature of the interacting proteins and the physiological relevance of the interactions should be fully clarified.

\section{2-3) Protein-protein interaction at the PDZ binding motif}

Until recently, information on protein-protein interactions has been quite limited for drug transporters. Yeast two-hybrid analysis first identified a specific interaction of the C-terminal cytosolic region of MRP2 
with the PDZ domain-containing protein PDZK1 (also designated as Diphor-1/NaPi-Cap1/CLAMP/CAP70) (Table 2)(Kocher et al., 1999). Thereafter, interaction analysis by Gilser et al. (2003) revealed the interaction of PDZK1 with several drug transporters, including urate transporter (URAT1), OCTN1 and Oatp5. To examine the overall pattern of the interaction of drug transporters with PDZ domain-containing proteins, we have recently performed yeast two-hybrid interaction analysis of the C-terminal cytosolic region of drug transporters with four PDZ domain-containing proteins which are known to interact with other SLC superfamily members (Kato et al., 2004) (Table 1). This screening clearly indicated specific interactions of certain drug transporters with PDZ proteins, and all the drug transporters that showed a positive interaction have a PDZ binding motif at their C-terminus (Table 1), suggesting that these C-terminal motifs act as a signal for specific interaction. These PDZ proteins include PDZK1, PDZK2 (also named NaPiCap2, and intestinal and kidney-enriched PDZ protein, IKEPP), NHERF1 and NHERF2 (SLC9A3R2, also named E3KARP, SIP-1 and TKA-1)(Table 1, Fig. 2). The interaction was confirmed by using recombinant C-terminal regions and PDZ proteins (Gisler et al., 2003; Anzai et al., 2004; Kato et al., 2004, 2005).

PDZK1 and PDZK2 have four PDZ domains in its structure (Fig. 2), each PDZ domain having been proposed to bind independently to a 
PDZ motif (Table 2). Yeast two-hybrid and pull-down studies using recombinant proteins have identified a number of interacting membrane proteins for each PDZ domain in PDZK1 (Table 2). Some of the membrane proteins can bind to only a single PDZ domain in PDZK1, whereas others can bind to 2 or 3 PDZ domains (Table 2, Fig. 2). For example, the G-terminal region in CFTR binds to PDZ3 with high affinity $(\mathrm{Kd}=8 \mathrm{nM})$, and to PDZ1 and PDZ4 with low affinity (Kd=100-200 $\mathrm{nM})$, but does not bind to PDZZ (Wang al, 2000) (Table 2, Fig. 2). Similaty, the C-terminal domain in URAT1 binds to PDZ1 with high affinity (Kd $=2$ $\mathrm{nM})$, and to PDZ2 and PDZ4 with low affinity (Kd = 300-500 nM), but does not bind to PDZ3 (Anzai et al., 2004) (Table 2, Fig. 2). The physiological relevance of such multiple binding domains in PDZK1 for each transporter has not yet been clarified, except that the tandem PDZ domains interacting with CFTR are essential for functional modulation by PDZK1 (Wang et al., 2000). The interaction potential among multiple domains may allow fine functional regulation of drug transporters.

Immunohistochemical and biochemical analyses have indicated that both PDZK1 and several drug transporters are colocalized on apical membranes of renal proximal tubular epithelial cells (Gisler et al., 2003; Anzai et al., 2004; Kato et al., 2004, 2005). In addition, NHERF1 can also bind to NHERF1 itself, NHERF2 and PDZK1 (Gisler et al., 2003; Lau and Hall 2001). These results suggest that drug transporters may be localized 
within a large protein complex consisting of several PDZ proteins (Gisler et al., 2003; Kato et al., 2004). Although the physiological significance of such a network should be clarified by further analysis, it may provide a structural basis for functional coupling of drug transporters. For example, PEPT2 might be localized in close proximity to NHE3, a $\mathrm{Na}^{+} / \mathrm{H}^{+}$exchanger which is expressed on apical membranes of renal proximal tubules, because PDZK1 can bind to PEPT2 and NHE3 at different PDZ domains (Table 2, Fig. 3). Alternatively, NHE3 may bind to NHERF1, which can then interact with PEPT2 indirectly through PDZK1 (Table 2, Fig. 3). Therefore, a precise understanding of the structural organization of each transporter protein could be important for estimating membrane transport efficacy for various substrates at apical membranes in the kidney.

Protein-protein interaction and protein network formation in the kidney have been extensively studied for NHE3, and the results indicate colocalization of NHE3 with other membrane proteins. These proteins include megalin, which belongs to the LDL receptor superfamily and is involved in renal reabsorption of various compounds and polypeptides, and dipeptidyl peptidase-IV (DPPIV, also known as CD26), which is a highly specific serine protease that cleaves $\mathrm{N}$-terminal dipeptides from peptides with a penultimate proline or alanine (Biemesderfer et al., 1999; Girardi et al., 2001). It should be noted however, that this network consists of distinct compartments, since NHE3 antibody can immunoprecipite DPPIV, but not 
sodium-phosphate cotransporter (NPT) 2, which is also expressed on apical membranes of renal proximal tubules, and can interact with NHERF1 and PDZK1 (Gisler et al., 2001) (Table 2). DPPIV and megalin can be independently co-precipitated with NHE3 by different NHE3 antibodies (Biemesderfer et al., 1999; Girardi et al., 2001), also supporting such distinct compartmentalization. In addition, Although protein-protein interaction studies have suggested possible formation of large protein complexes consisting of multiple transporters and PDZ proteins, no study has actually isolated or visualized such a complex. Thus, details of the organization of these membrane transporters remain to be clarified.

The PDZ binding signal in MRP2 also matches the protein kinase (PK) C phosphorylation site designated as [S/T]-X-[R/K]. Hegedus et al. (2003) reported, based on in vitro binding experiments, a high interaction potential with NHERF1 of the phosphorylated C-terminal peptide of MRP2. This may be compatible with the previous finding that PMA treatment resulted in mistargeting of MRP2 to the basolateral membrane in HepG2 cells (Kubitzb et al., 2001). Thus, at least certain types of PDZ domain-PDZ binding motif interaction may not represent just physical interaction, but may also be involved in regulation of intracellular trafficking and/or signaling. 


\section{PDZ adaptor proteins involved in regulation of expression and function of transporters}

3-1) PDZK1 family: Structure, expression and localization

Both PDZK1 and PDZK2 have PDZ dheins stume (Fig. 2) and they have $28 \%$ amino acid sequence identity in the case of the human orthologs. Since no other distinct structure than PDZ domains have been defined in these PDZK family proteins, these can be categorized as simple adaptors (Bezprozvanny and Maximov 2001) (Fig. 2). The primary structure of PDZK1 is highly conserved among mammalian species, with $78 \%$ identity between the human and mouse orthologs. This is also the case for PDZK2, since human PDZK2 has 81\% identity with mouse NaPiCap2, which is probably the mouse ortholog for PDZK2.

PDZK1 was identified by differential display-PCR techniques as a protein which is up-regulated in rats on a low-phosphate diet, and it increased the phosphate-transporting activity of NPT2 transfected into Xenopus laevis oocytes (Custer et al., 1997). PDZK1 was also identified as a PDZ domain-containing protein which is up-regulated in several carcinoma cell lines (Kocher et al., 1999) or increases cell-surface expression of HDL receptor scavenger receptor class B type I (SR-B1) (Ikemoto et al., 2000).

On the other hand, PDZK2 was first identified as NaPiCap2 in an adult mouse kidney cDNA library by yeast two-hybrid screening as an 
interacting partner for NPT2a (Gisler et al., 2001). Human PDZK2 was also identified by yeast two-hybrid screening as a regulator of guanylyl cyclase C, the heat-stable enterotoxin receptor (Scott et al., 2002). Thus, both PDZ proteins may interact with various types of cellular proteins.

In northern blot analysis, PDZK1 was detected in mouse liver, kidney, small intestine and testis, whereas PDZK2 was expressed only in kidney and small intestine (Gisler et al., 2001). Western blot analysis in mouse tissues revealed higher expression of PDZK1 in kidney, followed by liver and jejunum, significant expression being also observed in brain, lung and testis (Wang et al., 2000). In mouse kidney both PDZK1 and PDZK2 are immunostained on apical membranes exclusively in proximal tubules, and the immunostaining was uniform along the proximal tubules (S1, S2, and S3 segments) (Gisler et al., 2001). PDZK1 is strictly associated with the microvilli, whereas PDZK2 is predominantly located in the subapical compartment, faint immunostaining being also found throughout the cytoplasm, but not in the microvilli (Gisler et al., 2001).

In rabbits, mRNA and protein expression of PDZK1 is much lower in the colon than in the small intestine (Rossmann et al., 2005). On the other hand, in humans, gene expression of PDZK1 assessed by Northern blot analysis was observed in kidney, liver and small intestine (Wang et al., 2000). Northern blot analysis revealed PDZK2 mRNA expression almost exclusively in the kidney, with much lower levels in the small intestine and 
colon in humans. Immunohistochemical analysis revealed localization of PDZK2 on the apical surface in cells of the crypt and villus of human ileum and colon (Scott et al., 2002). Overall, these two PDZK1 family members are expressed on apical membranes in both kidney and small intestine of each species, although distinct localizations may also occur and be relevant to their specific physiological roles.

\section{3-2) NHERF family: Structure, expression and localization}

NHERF1 was first purified by means of biochemical techniques and cloned as a protein kinase A-mediated regulator of NHE in rabbit renal brush border membranes, whereas NHERF2 was identified by yeast two-hybrid analysis as a protein interacting with the C-terminal cytoplasmic region of NHE3 (Weinman et al., 1993, 1995; Yun et al., 1997). NHERF1 has high homology with NHERF2 ( 52\% identity for the human orthologs), both having two PDZ domains at the N-terminal side (Fig. 2). In contrast to the PDZK1 family members, which have only tandem PDZ domains in their structure (Fig. 2), NHERF1 and NHERF2 also have an ERM (ezrin-radixin-moesin) binding domain at their C-terminal region, which can directly bind to the FERM (band four-point-one, ERM) domain located at the N-terminal region of ERM family members (Bretscher et al., 2000, 2002; Voltz et al., 2001) (Fig. 2). 
In that sense, these NHERF family proteins can be categorized as complex adaptors (Bezprozvanny and Maximov 2001).

NHERF1 and NHERF Can fOM Oligomerization of NHERF1 and NHERF2 is differentially regulated: NHERF1/NHERF1 association has a relatively lower affinity, but has a higher affinity in the presence of the C-terminal ligand of transmembrane proteins, and it can be affected by a constitutively phosphorylated serine residue within NHERF1, whereas NHERF2/NHERF2 association has a relatively higher affinity and is only minimally affected by interaction with the C-terminal ligand (Lau and Hall 2001). Such characteristics of the intermolecular interactions may be important for stabilization of membrane proteins including transporters, in cell-surface membranes.

In the mouse, western blot analysis revealed strong expression of NHERF1 both in kidney and small intestine, with intermediate levels being observed in liver and stomach; NHERF2 protein is expressed abundantly in the lung, but its expression in the above organs is quite low (Ingraffea et al., 2002). In humans, mRNA expression, assessed by northern blot analysis, of both NHERF1 and NHERF2 was ubiquitous, except that NHERF1 mRNA was absent in lung and skeletal muscle (Yun et al., 1997).

Immunohistochemical analyses of NHERF family members have revealed their apical localization in kidney and small intestine, but 
localization in other subcellular compartments is also likely: in rat kidney, NHERF1 is immunostained most abundantly in the apical brush-border membrane, cytosol and, to a lesser degree, in the basolateral membranes of renal proximal tubules, but is not expressed in any other nephron structures (Wade et al., 2001). On the other hand, NHERF2 is strongly detected in the glomerulus and other vascular elements, and in the cortical and medullary collecting ducts, but is not clearly immunostained in proximal tubules (Wade et al., 2001). The predominant expression of NHERF1, but not NHERF2, in proximal tubules was also reported in mouse kidney (Ingraffea et al., 2002). Mouse proximal tubules express both NHERF1 and NHERF2, but NHERF1 is strongly expressed in microvilli in association with ezrin, whereas NHERF2 is weakly detected in the microvilli, but is expressed predominantly at the base of the microvilli in the vesicle-rich domain (Wade et al., 2003).

Immunohistochemical analysis in the rabbit small intestine revealed localization of NHERF1 on ileal brush border membranes (Kim et al., 2002). Localization of NHERF1 in the brush border of columnar epithelial cells in the small intestine was also found in mouse, with striking colocalization with ezrin (Ingraffea et al., 2002). In rat liver, NHERF1 is expressed on the apical domain of hepatocytes, whereas NHERF2 expression in hepatocytes was hardly detected (Fouassier et al., 2001). In mouse liver, NHERF1 is expressed in bile canaliculi of hepatocytes, 
colocalizing with radixin, while expression of NHERF2 was not detected (Ingraffea et al., 2002).

3-3) Effect of PDZ proteins on membrane transport in vitro

Experimental findings in vitro have suggested that PDZK1 directly regulates the cell-surface expression and/or functional activity of various types of transporters. Custer et al. (1997) first reported increased phosphate transport by NPT2 in the presence of PDZK1. Wang et al. (2000) suggested that PDZK1 promotes intermolecular interaction of CFTRs, leading to potentiation of the chloride channel activity. The C-terminus of CFTR can interact with three of the four PDZ domains (PDZ1, PDZ3 and PDZ4) in PDZK1 (Fig. 2, Table 2, Wang et al., 2000). Interestingly, a stimulatory effect on channel activity was seen with a bivalent monoclonal antibody for CFTR and PDZ3-4 of PDZK1, but not with PDZ1-2, PDZ2-3 nor PDZ3, suggesting that linkage of at least two CFTR molecules via the C-terminus is necessary for the stimulatory effect (Wang et al., 2000). Such bivalent PDZ domain-mediated functional modulation of CFTR was also observed with NHERF1 (Raghuram et al., 2001).

Regarding the stabilization of drug transporters, Anzai et al. (2004) found that coexpression of PDZK1 increases transport capacity for urate by URAT1 in HEK293 cells, and such an increase can be explained by an increase in cell-surface expression of URAT1 induced by PDZK1. 
On the other hand, transport of GlySar by PEPT2 and carnitine by OCTN2 was increased in HEK293 stably expressing PDZK1, and such an increase cannot be explained by the change in mRNA for PEPT2 or cell-surface expression of OCTN2, respectively (Kato et al., 2004, 2005). Coexpression of PDZK1 results in an approximately 6-fold increase in transport capacity for carnitine by OCTN2 with minimal change in transport affinity, whereas modulation of the transport function by PDZK1 is less marked for PEPT2 and URAT1 (Kato et al., 2004, 2005; Anzai et al., 2004). In all cases, transporter mutants with deletion of the last three or four amino acids at the C-terminus exhibited no increase in activity in the presence of PDZK1, suggesting that interaction of PDZK1 with the transporters is responsible for the stabilization and functional regulation of the transporters by PDZK1 (Anzai et al., 2004; Kato et al., 2004, 2005). In addition, PDZK1 is colocalized with URAT1 and OCTN2 on apical membranes in proximal tubules in kidney, and pull-down assay or immunoprecipitation also suggested the colocalization of those transporters with PDZK1 in vivo (Anzai et al., 2004; Kato et al., 2005). However, all the experimental evidence suggesting the modulation of drug transporters by PDZK1 has been obtained in vitro, except that essential role of PDZK1 in basolateral expression of Oatp1a1/Oatp1 in hepatocytes was recently demonstrated in vivo using PDZK1 knockout mice (Wang et al., 2005). 
Considering that cell-surface expression and/or functional activity of transporters are directly regulated by the PDZ proteins, at least in vitro, endogenous expression of the PDZ proteins may affect the expression and/or function of transporters either endogenously expressed or exogenously transfected in the cell lines used for in vitro assays. Actually, it has been demonstrated that PDZ domain-NPT2a interaction is essential for apical localization of the transporter in LLC-pK1 cells (Hernando et al., 2002). As shown in Table 3, endogenous expression of the four PDZ domain-containing proteins is relatively ubiquitous in various cell lines. This may at least partially explain the apparently functional expression of drug transporters in most cell lines (CHO, LLC-pK1, HEK293, HeLa, etc) that have been usually used for in vitro analysis of drug transporters (Table 3). However, it is sometimes observed that transporters exogenously transfected into cell lines do not express their proper function and/or are not targeted to plasma membranes. For example, endogenous NPT2a and exogenously transfected NPT2a are properly targeted to apical membranes in OK cells, whereas NPT2 transfected into LLC-pK1 cells is mainly localized on apical membranes, but weak expression is also found in the basolateral region (Hernando et al., 2000). On the other hand, NPT2a transfected into MDCK cells is detected equally at basolateral and apical membranes, and that transfected into Caco2 cells does not reach the membranes, but remains in the cytoplasm (Hernando et al., 2000, 2001). 
3-4) Gene knockout mice for assessing the physiological roles of PDZ proteins

Considering that PDZK1 can interact with various types of transporters through multiple PDZ domains in its structure and thereby regulate the expression and/or function of the membrane proteins (Fig. 2, Table 2), changes in the gene expression level of PDZK1 could possibly affect the expression and/or localization of membrane transporters, consequently affecting the membrane transport kinetics of various types of compounds. As a promising approach to analyze the physiological roles of PDZ proteins, PDZK1 gene knockout mice were first developed by Kocher et al. (2003a). PDZK1-deficient mice developed normally, did not display any gross phenotypic abnormalities, and exhibited apparently normal immunohistochemical localization of MRP2 and NPT2a in the kidney, probably due to functional compensation by other PDZ proteins (Kocher et al., 2003a). However, they exhibit an approximately two-fold elevation of plasma total cholesterol level, which is thought to result from a 95\% reduction in the HDL receptor scavenger receptor class B type I (SR-B1) gene product in the liver, with only a minimal change in its mRNA level (Kocher et al., 2003b).

In the PDZK1 knockout mouse, expression of NPT2a is decreased under a high-Pi diet condition, with a concomitant higher urinary fractional 
Pi excretion (Capuano et al., 2004). In the NHERF1 gene knockout mouse, on the other hand, NPT2 expression on brush border membranes in the kidney is lower than that in the wild-type mouse, NPT2 being aberrantly localized at internal sites in the renal proximal tubule cells, concomitantly with a higher urinary excretion of phosphate (Weinman et al., 2003a; Shenolikar et al., 2002). Although the NHERF1 knockout mouse exhibited normal blood electrolytes, smaller body weight than in the wild-type mouse was observed in females, and disorganized microvilli were seen in the small intestine (Morales et al., 2004). Thus, both NHERF1 and PDZK1 could be involved in cell-surface stabilization and/or expression of NPT2 at least under some conditions. In humans, NHERF1 is also expressed in the uppermost stratum granular layer of epidermis, and SNP in a putative RUNX1 binding site close to the NHERF1 gene is associated with psoriasis (Helms et al., 2003). Recent biopharmaceutical analysis has revealed functional expression of drug transporters in the skin (Li et al., 2005). Further analysis of the association of NHERF1 and drug transporters should improve our understanding of drug permeation in the skin.

\section{3-5) Regulation of PDZ proteins}

PDZ proteins can interact with other cellular proteins besides transporters, implying that transporter-PDZ protein interactions lead to further protein network formation. Both PDZ1 and PDZ4 in PDZK1 have 
been reported to interact with MAP17 (17-kD membrane-associated protein, also known as DD96, SPAP and pKe\#192), which is expressed in the proximal tubules of the kidney cortex, spermatids of the seminiferous tubules and upper stratum granulosum of normal epidermis keratinocytes (Blasco et al., 2003; Jaeger et al., 2000). Human MAP17 has 114 amino acids with a PDZ binding motif (-TPM) at the extreme C-terminus. MAP17 spans the cellular membranes twice, with both the $\mathrm{N}$ - and C-termini being inside the cells (Blasco et al., 2003). MAP17 was first identified by means of a differential display technique as a molecule highly up-regulated in human renal cell carcinoma (Kocher et al., 1995). MAP17 seems to exhibit specific interaction with PDZK1, since GST fusion protein only with PDZK1, but not with PDZK2 or NHERF1 can pull-down MAP17 in renal brush border membrane vesicles (Pribanic et al., 2003).

MAP17 is co-immunoprecipitated with PDZK1 both in liver and kidney of mouse (Silver et al., 2003), suggesting an interaction of the two proteins in vivo. MAP17 exhibited apical localization after transfection into OK cells, showing colocalization with endogenous NPT2a (Pribanic et al., 2003). On the other hand, PDZK1 showed a cytoplasmic distribution when transfected alone into OK cells, whereas coexpression of PDZK1 with MAP17 resulted in apical colocalization of the two proteins (Pribanic et al., 2003). Deletion of the last three amino acids in MAP17 shifted its subcellular localization into both apical and cytoplasmic regions, but it still 
exhibited colocalization with PDZK1 (Pribanic et al., 2003). Thus, localization of PDZK1 is regulated by MAP17, at least in transfectant systems with in vitro cell lines. On the other hand, in vivo overexpression of MAP17 results in the absence of PDZK1, without any effect on expression of PDZK2, in mouse liver (Silver et al., 2003). In kidney, PDZK1 is equally distributed throughout the whole proximal tubules (Pribanic et al., 2003), whereas MAP17 exhibited higher apical localization in S1 than S3 segments (Pribanic et al., 2003). Further studies are needed to establish the physiological significance of the MAP17-PDZK1 interaction in vivo.

On the other hand, both NHERF1 and NHERF2 have an ERM binding domain at their C-terminal region (Fig. 2); this can bind directly to the FERM (band four-point-one, ERM) domain located at the N-terminal region in members of the ERM family (Bretscher et al., 2000, 2002; Voltz et al., 2001). The FERM domain can also interact directly with C-ERMAD (C-terminal ERM association domain) in ERM proteins, forming an inactive state. Activation of ERM protein is accomplished by C-terminal phosphorylation, resulting in relief of the FERM/C-ERMAD interaction and regeneration of interaction potential of FERM with NHERFs. This activation is compatible with the observation of high levels of phosphorylated ERM proteins in membrane fractions in both kidney and intestine (Morales et al., 2004). The C-terminal region in ERM proteins can 
interact with filamentous (F)-actin, suggesting a fundamental role in the structural organization of polarized epithelial cells by connecting F-actin to plasma membrane proteins, including transporters. Ezrin is highly expressed both in kidney and small intestine, whereas radixin is the major ERM protein in liver.

Interestingly, expression of ezrin, especially phosphorylated ezrin, on brush membranes in both kidney and small intestine is clearly down-regulated in NHERF1 gene knockout mouse, demonstrating that NHERF1 is required for the maintenance of activated ezrin on brush border membranes (Morales et al., 2004). In small intestine where ezrin is the only ERM protein expressed, disorganized microvilli with an increase in the number of goblet cells are observed in NHERF1 knockout mice, suggesting a physiological role of NHERF1 in apical membrane organization (Morales et al., 2004). In radixin knockout mouse, the serum concentration of conjugated bilirubin is increased compared with wild-type mouse, showing

a similar phenotype to human conjugated hyperbilirubinemia in Dubin-Johnson syndrome (Kikuchi et al., 2002), which results from genetic deficiency in MRP2

\section{Involvement of PPAR- $\alpha$ in gene expression of drug transporters and}

\section{PDZ proteins}


PPAR $\alpha$ is a member of the large nuclear receptor superfamily and regulates expression of genes responsible for fatty acid $\beta$-oxidation and energy homeostasis. PPAR $\alpha$ is highly expressed in liver, heart muscle, kidney and skeletal muscle, which have relatively high mitochondrial and peroxisomal fatty acid $\beta$-oxidation rates. PPAR $\alpha$ agonists include fibric acid derivatives (fibrates), nonsteroidal anti-inflammatory drugs, and saturated and unsaturated fatty acids. PPAR $\alpha$ is also activated by glucocorticoids and fasting. Expression of Mdr2mRNA was 5-fold increased in fasted wild-type mice, but increased only marginally in PPAR $\alpha(-/-)$ mice. Fibrates have been used to treat dyslipidemia because they increase high-density lipoprotein cholesterol (HDL) and decrease triglyceride in serum (Berger et al., 2005; van Raalte et al., 2004; Goikoetxea et al., 2004). PPAR $\alpha$ is the target of drugs that are effective in the treatment of metabolic disorders (atherogenesis, cardiovascular disease, type 2 diabetes, etc.). PPAR $\alpha / \gamma$ dual agonists are also being developed.

Repeated administration of fibrates such as ciprofibrate and fenofibrate caused almost complete down-regulation of PDZK1 and SR-B1, and this mainly occurs via PPAR $\alpha$ since PPAR $\alpha(-/-)$ mice exhibited no down-regulation (Mardones et al., 2003). Considering that SR-B1 is the major HDL receptor in liver and its cell-surface expression is highly regulated by PDZK1, the down-regulation of SR-B1 could be at least partially due to the down-regulation of PDZK1, and could explain in part 
the increase in HDL level after treatment with fibrates. However, a recent finding indicated the presence of a PDZK1-independent pathway for SR-B1 down-regulation (Lan et al., 2005), suggesting the presence of other molecular machinery for stabilizing SR-B1 in hepatocytes.

After treatment of mice with PPAR $\alpha$ agonists such as clofibrate, ciprofibrate and di(2-ethylhexyl)phthalate, the mRNAs for hepatic transporters, Oatp1a1/Oatp1, Oatp2a1/PGT and Oatp2b1/Oatp9, were decreased, whereas that for Mrp3 was increased without any significant change in that for Mrp2 (Cheng et al., 2005; Maher et al., 2005). Such down-regulation of Oatp1a1/Oatp1 was previously reported at both the mRNA and protein levels in mouse liver, and such transcriptional regulation occurs via PPAR $\alpha$-activation (Kok et al., 2003). On the other hand, ciprofibrate treatment increases expression of Oatp1a1/Oatp1, with a decrease in Mrp2, as revealed by Western blot analysis of hepatic membrane fraction in rats (Chandra et al., 2005), suggesting species difference in PPAR $\alpha$ activation. The efflux of a non-metabolized model substrate, 5(and 6)-carboxy-2',7'dichlorofluorescein (CDF) from liver to bile was found to be decreased in a rat liver perfusion system, and this could be compatible with the down-regulation of Mrp2 (Chandra et al., 2005). On the other hand, hepatic uptake of CDF is decreased after clofibrate treatment, and this cannot be simply explained by up-regulation of Oatp1a1/Oatp1 (Chandra et al., 2005). Both rat and mouse 
Oatp1a1/Oatp1 interacts with PDZK1, and PDZK1 is responsible for sinusoidal localization of Oatp1a1/Oatp1, as revealed in PDZK1 gene knockout mouse (Wang et al., 2005). Considering down-regulation of PDZK1 by treatment with fibrates (Mardones et al., 2003), mislocalization of Oatp transporters by the down-regulation of PDZK1 might be involved in the change in hepatic membrane transport by the fibrate treatment.

Juvenile visceral steatosis (jvs) mice which have a hereditary deficiency of the OCTN2 gene exhibit fat deposition and mitochondrial abnormalities in the liver. The high-affinity site for uptake of carnitine was absent in hepatocytes obtained from jvs mouse (Yokogawa et al., 1998). Considering that carnitine is efficiently transported by OCTN2, these results suggest that OCTN2 is functionally expressed in sinusoidal membranes of hepatocytes and is possibly involved in lipid homeostasis via transport of carnitine, which is essential for $\beta$-oxidation of fatty acids. Considering that PDZK1 is a functional modulator of OCTN2, down-regulation of PDZK1 after treatment with fibrates may affect carnitine uptake by OCTN2, leading to a change in fatty acid metabolism. Further studies are needed to clarify the pharmacological significance of the OCTN2/PDZK1 system in energy homeostasis in liver.

There are large species differences in the expression of PPAR $\alpha$. Human liver has less than one-tenth the levels of PPAR $\alpha$ expression observed in mice and rats. Therefore, PPAR $\alpha$-mediated gene activation in 
humans seems unlikely to be predicted based on the phenotype observed in rodents.

\section{Conclusions}

Recent progress in the analysis of protein-protein interactions has revealed that the expression and/or function of at least some types of drug transporters are regulated by PDZ domain-containing proteins. Various transporters localized at apical membranes in kidney and small intestine are thought to be incorporated into protein networks (Fig. 3). Drug transporters are categorized in several families, and often have overlapping substrate specificity and cellular localization in the body, suggesting the presence of functional redundancy. Similarly, PDZ proteins have overlapping binding specificity (Table 1) and cellular localization, and data obtained in gene knockout mice suggest the occurrence of compensation of physiological function. Considering the multiple interactions between PDZ domains and cytosolic domains of various transporters, PDZ proteins have the potential to influence membrane transport of many substrates, possibly affecting disposition of these substrates in the body. The physiological roles of PDZ proteins should be clarified by further extensive analyses. 


\section{REFERENCES}

Anderson, C.M., Mendoza, M.E., Kennedy, D.J., Raldua, D., Thwaites, D.T.. 2003. Inhibition of intestinal dipeptide transport by the neuropeptide VIP is an anti-absorptive effect via the VPAC1 receptor in

a human enterocyte-like cell line (Caco-2). Br. J. Pharmacol. 138, 564-573.

Anzai, N., Miyazaki, H., Noshiro, R., Khamdang, S., Chairoungdua, A., Shin, H.J., Enomoto, A., Sakamoto, S., Hirata, T., Tomita, K., Kanai, Y., Endou H., 2004. The multivalent PDZ domain-containing protein PDZK1 regulates transport activity of renal urate-anion exchanger URAT1 via its C terminus. J. Biol. Chem. 279, 45942-45950.

Benet, L.Z., Cummins, C.L., Wu, C.Y., 2004. Unmasking the dynamic interplay between efflux transporters and metabolic enzymes. Int. J. Pharm. 277, 3-9.

Berger, J.P., Akiyama, T.E., Meinke, P.T., 2005. PPARs: therapeutic targets for metabolic disease. Trends Pharmacol Sci. 26, 244-251.

Bezprozvanny, I., Maximov, A., 2001. Classification of PDZ domains. FEBS Lett. 509, 457-462.

Biber, J., Gisler, S.M., Hernando, N., Wagner, C.A., Murer, H., 2004. PDZ interactions and proximal tubular phosphate reabsorption. Am. J. Physiol. 287, F871-F875. 
Biemesderfer, D., Nagy, T., DeGray, B., Aronson, P.S., 1999. Specific association of megalin and the $\mathrm{Na}+/ \mathrm{H}+$ exchanger isoform NHE3 in the proximal tubule. J. Biol. Chem. 274, 17518-17524.

Blasco, T., Aramayona, J.J., Alcalde, A.I., Catalan, J., Sarasa, M., Sorribas, V., 2003. Rat kidney MAP17 induces cotransport of Na-mannose and Na-glucose in Xenopus laevis oocytes. Am. J. Physiol. Renal. Physiol. 285, F799-F810.

Bonifacino, J.S., Traub, L.M., 2003. Signals for sorting of transmembrane proteins to endosomes and lysosomes. Annu. Rev. Biochem. 72, 395-447.

Bretscher, A., Chambers, D., Nguyen, R., Reczek, D., 2000. ERM-Merlin and EBP50 protein families in plasma membrane organization and function. Annu. Rev. Cell Dev. Biol. 16, 113-143.

Bretscher, A., Edwards, K., Fehon, R.G., 2002. ERM proteins and merlin: integrators at the cell cortex. Nat. Rev. Mol. Cell Biol. 3, 586-599.

Brone, B., Eggermont, J., 2005. PDZ proteins retain and regulate membrane transporters in polarized epithelial cell membranes. Am. J. Physiol. 288, C20-C29.

Campo, C., Mason, A., Maouyo, D., Olsen, O., Yoo, D., Welling, P.A., 2005. Molecular mechanisms of membrane polarity in renal epithelial cells. Rev. Physiol. Biochem. Pharmacol. 153, 47-99. 
Capuano, P., Bacic, D., Stange, G., Hernando, N., Kaissling, B., Pal, R., Kocher, O., Biber, J., Wagner, C.A., Murer, H., 2004. Expression and regulation of the renal $\mathrm{Na} /$ phosphate cotransporter NaPi-IIa in a mouse model deficient for the PDZ protein PDZK1. Pflugers. Arch. 449, 392-402.

Chandra, P., Johnson, B.M., Zhang, P., Pollack, G.M., Brouwer, K.L., 2005. Modulation of hepatic canalicular or basolateral transport alters hepatobiliary disposition of a model organic anion in the isolated perfused rat liver. Drug Metab. Dispos. in press.

Cheng, X., Maher, J.M., Dieter, M.Z., Klaassen, C.D., 2005. Regulation of mouse organic anion transporting polypeptides (Oatps) in liver by prototypical microsome enzyme inducers that activate distinct transcriptional factor pathways. Drug Metab. Dispos., in press.

Custer, M., Spindler, B., Verrey, F., Murer, H., Biber, J. 1997. Identification of a new gene product (diphor-1) regulated by dietary phosphate. Am. J. Physiol. 273, F801-F806.

Daniel, H., 2004. Molecular and integrative physiology of intestinal Peptide transport. Annu. Rev. Physiol., 66, 361-384.

Enerson, B.E., Drewes, L.R., 2003. Molecular features, regulation, and function of monocarboxylate transporters: implications for drug delivery. J. Pharm. Sci. 92, 1531-1544. 
Fouassier, L., Duan, C.Y., Feranchak, A.P., Yun, C.H., Sutherland, E., Simon, F., Fitz, J.G., Doctor, R.B., 2001. Ezrin-radixin-moesin-binding phosphoprotein 50 is expressed at the apical membrane of rat liver epithelia Hepatology. 33, 166-176.

Girardi, A.C., Degray, B.C., Nagy, T., Biemesderfer, D., Aronson, P.S., 2001. Association of $\mathrm{Na}(+)-\mathrm{H}(+)$ exchanger isoform NHE3 and dipeptidyl peptidase IV in the renal proximal tubule. J. Biol. Chem. 276, 46671-46677.

Gisler, S.M., Stagljar, I., Traebert, M., Bacic, D., Biber, J., Murer, H., 2001. Interaction of the type IIa Na/Pi cotransporter with PDZ proteins. J. Biol. Chem. 276, 9206-9213.

Gisler, S.M., Pribanic, S., Bacic, D., Forrer, P., Gantenbein, A., Sabourin, L.A., Tsuji, A., Zhao, Z.S., Manser, E., Biber, J., Murer, H., 2003. PDZK1: I. a major scaffolder in brush borders of proximal tubular cells. Kidney Int. 64, 1733-1745.

Goikoetxea, M.J., Beaumont, J., Diez, J., 2004. Peroxisome proliferator-activated receptor alpha and hypertensive heart disease. Drugs. 64 (Suppl 2), 9-18.

Hagenbuch, B., Meier, P.J., 2003. Organic anion transporting polypeptides of the OATP/ SLC21 family: phylogenetic classification as OATP/ SLCO superfamily, new nomenclature and molecular/functional properties. Pflugers Arch. 447, 653-665. 
Halestrap, A.P., Meredith, D., 2004. The SLC16 gene family-from monocarboxylate transporters (MCTs) to aromatic amino acid transporters and beyond. Pflugers Arch. 447, 619-628.

Han, H. K., Amidon, G. L., 2000. Targeted prodrug design to optimize drug delivery. AAPS PharmSci., 2, E6.

Harris, M.J., Kuwano, M., Webb, M., Board, P.G., 2001. Identification of the apical membrane-targeting signal of the multidrug resistance-associated protein 2 (MRP2/MOAT). J. Biol. Chem. 276, 20876-20881.

He, J., Lau, A.G., Yaffe, M.B., Hall, R.A., 2001. Phosphorylation and cell cycle-dependent regulation of $\mathrm{Na}^{+} / \mathrm{H}^{+}$exchanger regulatory factor- 1 by Cdc2 kinase. J. Biol. Chem. 276, 41559-41565.

Hegedus, T., Sessler, T., Scott, R., 2003. C-terminal phosphorylation of MRP2 modulates its interaction with PDZ proteins. Biochem. Biophys. Res. Commun. 302, 454-461.

Helms, C., Cao, L., Krueger, J.G., Wijsman, E.M., Chamian, F., Gordon, D., Heffernan, M., Daw, J.A., Robarge, J., Ott, J., Kwok, P.Y., Menter, A., Bowcock, A.M., 2003. A putative RUNX1 binding site variant between SLC9A3R1 and NAT9 is associated with susceptibility to psoriasis. Nat Genet. 35, 349-356.

Hernando, N., Sheikh, S., Karim-Jimenez, Z., Galliker, H., Forgo, J., Biber, J., Murer, H., 2000. Asymmetrical targeting of type II Na-P(i) 
cotransporters in renal and intestinal epithelial cell lines. Am. J. Physiol. 278, F361-F368.

Hernando, N., Karim-Jimenez, Z., Biber, J., Murer, H., 2001. Molecular determinants for apical expression and regulatory membrane retrieval of the type IIa Na/Pi cotransporter. Kidney Int. 60, 431-435.

Hernando, N., Deliot, N., Gisler, S.M., Lederer, E., Weinman, E.J., Biber, J., Murer, H., 2002. PDZ-domain interactions and apical expression of type IIa Na/P(i) cotransporters. Proc. Natl. Acad. Sci. U. S. A. 99, 11957-11962.

Hung, A.Y., Sheng, M., 2002; PDZ Domains: Structural Modules for Protein Complex Assembly. J. Biol. Chem. 277, 5699-5702.

Ikemoto, M., Arai, H., Feng, D., Tanaka, K., Aoki, J., Dohmae, N., Takio, K., Adachi, H., Tsujimoto, M., Inoue, K., 2000. Identification of a PDZ-domain-containing protein that interacts with the scavenger receptor class B type I. Proc. Natl. Acad. Sci. U. S. A. 97, 6538-6543.

Ingraffea, J., Reczek, D., Bretscher, A., 2002. Distinct cell type-specific expression of scaffolding proteins EBP50 and E3KARP: EBP50 is generally expressed with ezrin in specific epithelia, whereas E3KARP is not. Eur. J. Cell Biol. 81, 61-68.

Jaeger, C., Schaefer, B.M., Wallich, R., Kramer, M.D., 2000. The membrane-associated protein pKe\#192/MAP17 in human keratinocytes. J. Invest. Dermatol. 115, 375-380. 
Jonker, J,W,, Schinkel, A.H., 2004. Pharmacological and physiological functions of the polyspecific organic cation transporters: OCT1, 2, and 3 (SLC22A1-3). J. Pharmacol. Exp. Ther. 308, 2-9.

Kato, Y., Yoshida, K., Watanabe, C., Sai, Y., Tsuji, A., 2004. Screening of the interaction between xenobiotic transporters and PDZ proteins. Pharm. Res. 21, 1886-1894.

Kato, Y., Sai, Y., Yoshida, K., Watanabe, C., Hirata, T., Tsuji, A., 2005. PDZK1 directly regulates the function of organic cation/carnitine transporter OCTN2. Mol. Pharmacol. 67, 734-743.

Kennedy, D.J., Leibach, F.H., Ganapathy, V., and Thwaites, D.T., 2002. Optimal absorptive transport of the dipeptide glycylsarcosine is dependent on functional $\mathrm{Na}^{+} / \mathrm{H}^{+}$exchange activity. Pflügers Archiv. 445, 139-146.

Kikuchi, S., Hata, M., Fukumoto, K., Yamane, Y., Matsui, T., Tamura, A., Yonemura, S., Yamagishi, H., Keppler, D., Tsukita, S., Tsukita, S., 2002. Radixin deficiency causes conjugated hyperbilirubinemia with loss of Mrp2 from bile canalicular membranes. Nat Genet. 31, 320-325.

Kim, J.H., Lee-Kwon, W., Park, J.B., Ryu, S.H., Yun, C.H., Donowitz, M., 2002. $\mathrm{Ca}(2+)$-dependent inhibition of $\mathrm{Na}+/ \mathrm{H}+$ exchanger 3 (NHE3) requires an NHE3-E3KARP-alpha-actinin-4 complex for oligomerization and endocytosis. J. Biol. Chem. 277, 23714-23724. 
Kobayashi, D., Nozawa, T., Imai, K., Nezu, J., Tsuji, A., Tamai, I., 2003. Involvement of human organic anion transporting polypeptide OATP-B (SLC21A9) in pH-dependent transport across intestinal apical membrane. J. Pharmacol. Exp. Ther. 306, 703-708.

Kocher, O., Cheresh, P., Brown, L.F., Lee, S.W., 1995. Identification of a novel gene, selectively up-regulated in human carcinomas, using the differential display technique. Clin. Cancer Res. 1, 1209-1215.

Kocher, O., Cheresh, P., Lee, S.W., $\quad$ 1996. Identification and partial characterization of a novel membrane-associated protein (MAP17) up-regulated in human carcinomas and modulating cell replication and tumor growth. Am. J. Pathol. 149, 493-500.

Kocher, O., Comella, N., Tognazzi, K., Brown, L.F., 1998. Identification and partial characterization of PDZK1: a novel protein containing PDZ interaction domains. Lab. Invest. 78, 117-125.

Kocher, O., Comella, N., Gilchrist, A., Pal, R., Tognazzi, K., Brown, L.F., Knoll, J.H., 1999. PDZK1, a novel PDZ domain-containing protein up-regulated in carcinomas and mapped to chromosome 1q21, interacts with cMOAT (MRP2), the multidrug resistance-associated protein. Lab. Invest. 79, 1161-1170.

Kocher, O., Pal, R., Roberts, M., Cirovic, C., Gilchrist, A., 2003(a), Targeted disruption of the PDZK1 gene by homologous recombination. Mol. Cell Biol. 23, 1175-1180. 
Kocher, O., Yesilaltay, A., Cirovic, C., Pal, R., Rigotti, A., Krieger, M., 2003(b). Targeted disruption of the PDZK1 gene in mice causes tissue-specific depletion of the high density lipoprotein receptor scavenger receptor class B type I and altered lipoprotein metabolism. J. Biol. Chem. 278, 52820-52825.

Kok, T., Bloks, V.W., Wolters, H., Havinga, R., Jansen, P.L., Staels, B., Kuipers, F., 2003. Peroxisome proliferator-activated receptor alpha (PPARalpha)-mediated regulation of multidrug resistance 2 (Mdr2) expression and function in mice. Biochem, J. 369, 539-547.

Kubitz, R., Huth, C., Schmitt, M., Horbach, A., Kullak-Ublick, G., Haussinger, D., 2001. Protein kinase C-dependent distribution of the multidrug resistance protein 2 from the canalicular to the basolateral membrane in human HepG2 cells. Hepatology. 34, 340-350.

Kunta, J.R., Sinko, P.J., 2004. Intestinal drug transporters: in vivo function and clinical importance. Curr. Drug Metab. 5, 109-124.

Lan, D., Silver, D.L., 2005. Fenofibrate Induces a Novel Degradation Pathway for Scavenger Receptor B-I Independent of PDZK1. J. Biol. Chem. 280, 23390-23396.

Lau, A.G., Hall, R.A., 2001. Oligomerization of NHERF-1 and NHERF-2 PDZ domains: differential regulation by association with receptor carboxyl-termini and by phosphorylation. Biochemistry. 40, 8572-8580. 
Lee-Kwon, W., Kawano, K., Choi, J.W., Kim, J.H., Donowitz, M., 2003. Lysophosphatidic acid stimulates brush border $\mathrm{Na}^{+} / \mathrm{H}^{+}$exchanger 3 (NHE3) activity by increasing its exocytosis by an NHE3 kinase A regulatory protein-dependent mechanism. J. Biol. Chem. 278, 16494-16501.

Li, Q., Kato, Y., Sai, Y., Imai, T., Tsuji, A., 2005. Multidrug resistance-associated protein 1 functions as an efflux pump of xenobiotics in the skin. Pharm. Res., in press.

Maher, J.M., Cheng, X., Slitt, A.L., Dieter, M.Z., Klaassen, C.D., 2005. Induction of the multidrug resistance-associated protein family of transporters by chemical activators of receptor-mediated pathways in mouse liver. Drug Metab. Dispos. 33, 956-962.

Malmberg, E.K., Andersson, C.X., Gentzsch, M., Chen, J.H., Mengos, A., Cui, L., Hansson, G.C., Riordan, J.R.m 2004. Bcr (breakpoint cluster region) protein binds to PDZ-domains of scaffold protein PDZK1 and vesicle coat protein Mint3. J. Cell Sci. 117, 5535-5341.

Mardones, P., Pilon, A., Bouly, M., Duran, D., Nishimoto, T., Arai, H., Kozarsky, K.F., Altayo, M., Miquel, J.F., Luc, G., Clavey, V., Staels, B., Rigotti, A., 2003. Fibrates down-regulate hepatic scavenger receptor class B type I protein expression in mice. J. Biol. Chem. 278, 7884-7890. 
Marzolini, C., Tirona, R.G., Kim, R.B., 2004. Pharmacogenomics of the OATP and OAT families. Pharmacogenomics 5, 273-282.

Morales, F.C., Takahashi, Y., Kreimann, E.L., Georgescu, M.M., 2004. Ezrin-radixin-moesin (ERM)-binding phosphoprotein 50 organizes ERM proteins at the apical membrane of polarized epithelia. Proc. Natl. Acad. Sci. USA. 101, 17705-17710.

Nezu, J., Tamai, I., Oku, A., Ohashi, R., Yabuuchi, H., Hashimoto, N., Nikaido, H., Sai, Y., Koizumi, A., Shoji, Y., Takada, G., Matsuishi, T., Yoshino, M., Kato, H., Ohura, T., Tsujimoto, G., Hayakawa, J., Shimane, M., Tsuji, A., 1999. Primary systemic carnitine deficiency is caused by mutations in a gene encoding sodium ion-dependent carnitine transporter. Nat Genet 21, 91-94.

Nielsen, C.U. Brodin, B., 2003. Di/tri-peptide transporters as drug delivery targets: regulation of transport under physiological and patho-physiological conditions. Curr. Drug Targets 4, 373-388.

Nies, A.T., Konig, J., Cui, Y., Brom, M., Spring, H., Keppler, D., 2002. Structural requirements for the apical sorting of human multidrug resistance protein 2 (ABCC2). Eur. J. Biochem. 269, 1866-1876.

Ohashi, R., Tamai, I., Nezu, J., Nikaido, H., Hashimoto, N., Oku, A., Sai, Y., Shimane, M., Tsuji, A., 2001. Molecular and physiological evidence for multifunctionality of carnitine/organic cation transporter OCTN2. Mol. Pharmacol. 59, 358-366. 
Palacin, M., Kanai, Y., 2004. The ancillary proteins of HATs: SLC3 family of amino acid transporters. Pflugers Arch. 447, 490-494.

Nozawa, T., Imai, K., Nezu, J., Tsuji, A., Tamai, I., 2004. Functional characterization of $\mathrm{pH}$-sensitive organic anion transporting polypeptide OATP-B in human. J. Pharmacol. Exp. Ther. 308, 438-445.

Park, M., Ko, S.B., Choi, J.Y., Muallem, G., Thomas, P.J., Pushkin, A., Lee, M.S., Kim, J.Y., Lee, M.G., Muallem, S., Kurtz, I., 2002. The cystic fibrosis transmembrane conductance regulator interacts with and regulates the activity of the $\mathrm{HCO}^{-}$salvage transporter human $\mathrm{Na}^{+}-\mathrm{HCO}^{-}$ cotransport isoform 3. J. Biol. Chem. 277, 50503-50509.

Pribanic, S., Gisler, S.M., Bacic, D., Madjdpour, C., Hernando, N., Sorribas, V., Gantenbein, A., Biber, J., Murer, H., 2003. Interactions of MAP17 with the NaPi-IIa/PDZK1 protein complex in renal proximal tubular cells. Am. J. Physiol. 285, F784-F791.

van Raalte, D.H., Li, M., Pritchard, P.H., Wasan, K.M., 2004. Peroxisome proliferator-activated receptor (PPAR)-alpha: a pharmacological target with a promising future. Pharm Res. 21, 1531-1538.

Raghuram, V., Mak, D-O.D., Foskett, J.K., 2001. Regulation of cystic fibrosis transmembrane conductance regulator single-channel gating by bivalent PDZ-domain-mediated interaction. Proc. Natl. Acad. Sci. USA 98, 1300-1305.

Rossmann, H., Jacob, P., Baisch, S., Hassoun, R., Meier, J., Natour, D., 
Yahya, K., Yun, C., Biber, J., Lackner, K.J., Fiehn, W., Gregor, M., Seidler, U., Lamprecht, G., 2005. The CFTR associated protein CAP70 interacts with the apical $\mathrm{Cl}^{-} / \mathrm{HCO}_{3}{ }^{-}$exchanger DRA in rabbit small intestinal mucosa. Biochemistry. 44, 4477-4487.

Rodriguez-Boulan, E., Kreitzer, G., Musch, A., 2005. Organization of vesicular trafficking in epithelia. Nat. Rev. Mol. Cell. Biol. 6, 233-247.

Sai, Y., Tsuji, A., 2004. Transporter-mediated drug delivery: recent progress and experimental approaches. Drug Discov. Today. 9, 712-720.

Schreiber, R., Boucherot, A., Murle, B., Sun, J., Kunzelmann, K., 2004. Control of epithelial ion transport by $\mathrm{Cl}^{-}$and PDZ proteins. J. Membr. Biol. 199, 85-98.

Scott, R.O., Thelin, W.R., Milgram, S.L., 2002. A novel PDZ protein regulates the activity of guanylyl cyclase $\mathrm{C}$, the heat-stable enterotoxin receptor. J. Biol. Chem. 277, 22934-22941.

Shenolikar, S., Voltz, J.W., Minkoff, C.M., Wade, J.B., Weinman, E.J., 2002. Targeted disruption of the mouse NHERF-1 gene promotes internalization of proximal tubule sodium-phosphate cotransporter type IIa and renal phosphate wasting. Proc. Natl. Acad. Sci. USA 99, 11470-11475.

Shenolikar, S., Voltz, J.W., Cunningham, R., Weinman, E.J., 2004. Regulation of ion transport by the NHERF family of PDZ proteins. Physiology 19, 362-369. 
Shitara, Y., Sato, H., Sugiyama, Y., 2004. Evaluation of drug-drug interaction in the hepatobiliary and renal transport of drugs. Annu. Rev. Pharmacol. Toxicol. 45, 689-723.

Silver. D.L., Wang, N., Vogel, S., 2003. Identification of small PDZK1-associated protein, DD96/MAP17, as a regulator of PDZK1 and plasma high density lipoprotein levels. J. Biol. Chem. 278, 28528-28532.

Tamai, I., Ohashi, R., Nezu, J., Yabuuchi, H., Oku, A., Shimane, M., Sai, Y., Tsuji, A., 1998. Molecular and functional identification of sodium ion-dependent, high affinity human carnitine transporter OCTN2. J. Biol. Chem. 273, 20378-20382.

Tamai, I., Ohashi, R., Nezu, J., Sai, Y., Kobayashi, D., Oku, A., Shimane, M., Tsuji, A., 2000. Molecular and functional characterization of organic cation/carnitine transporter family in mice. J Biol Chem. 275, 40064-40072.

Tamai, I., Nakanishi, T., Kobayashi, D., China, K., Kosugi, Y., Nezu, J., Sai, Y., Tsuji, A., 2004. Involvement of OCTN1 (SLC22A4) in pH-dependent transport of organic cations. Mol. Pharm. 1, 57-66.

Thwaites, D.T., Kennedy, D.J., Raldua, D., Anderson, C., Mendoza, M.E., Bladen, C.L., Simmons, N.L., 2002. $\mathrm{H}^{+} /$dipeptide absorption across the human intestinal epithelium is controlled indirectly via a functional $\mathrm{Na} / \mathrm{H}$ exchanger. Gastroenterology 122, 1322-1333. 
Tsuji, A., Tamai, I., 1996. Carrier-mediated intestinal transport of drugs. Pharm Res. 13, 963-977.

Voltz, J.W., Weinman, E.J., Shenolikar, S., 2001. Expanding the role of NHERF, a PDZ-domain containing protein adapter, to growth regulation. Oncogene. 20, 6309-6314.

Wade, J.B., Welling, P.A., Donowitz, M., Shenolikar, S., Weinman, E.J., 2001. Differential renal distribution of NHERF isoforms and their colocalization with NHE3, ezrin, and ROMK. Am, J, Physiol. 280, C192-C198.

Wade, J.B., Liu, J., Coleman, R.A., Cunningham, R., Steplock, D.A., Lee-Kwon, W., Pallone, T.L., Shenolikar, S., Weinman, E.J., 2003. Localization and interaction of NHERF isoforms in the renal proximal tubule of the mouse. Am. J. Physiol. 285, C1494-C1503.

Wang, P., Wang, J.J., Xiao, Y., Murray, J.W., Novikoff, P.M., Angeletti, R.H., Orr, G.A., Lan, D., Silver, D.L., Wolkoff, A.W., 2005. Interaction with PDZK1 is required for expression of organic anion transporting protein 1A1 (OATP1A1) on the hepatocyte surface. J. Biol. Chem., in press.

Wang, S., Yue, H., Derin, R.B., Guggino, W.B., Li, M., 2000. Accessory protein facilitated CFTR-CFTR interaction, a molecular mechanism to potentiate the chloride channel activity. Cell 103, 169-179. 
Weinman, E.J., Steplock, D., Shenolikar, S., 1993. cAMP-mediated inhibition of the renal brush border membrane $\mathrm{Na}+-\mathrm{H}+$ exchanger requires a dissociable phosphoprotein cofactor. J. Clin. Invest. 92, $1781-1786$.

Weinman, E.J., Steplock, D., Wang, Y., Shenolikar, S., 1995. Characterization of a protein cofactor that mediates protein kinase A regulation of the renal brush border membrane $\mathrm{Na}(+)-\mathrm{H}+$ exchanger. $\mathrm{J}$. Clin. Invest. 95, 2143-2149.

Weinman, E.J., Evangelista, C.M., Steplock, D., Liu, M.Z., Shenolikar, S., Bernardo, A., 2001. Essential role for NHERF in cAMP-mediated inhibition of the $\mathrm{Na}^{+}-\mathrm{HCO}_{3}{ }^{-}$co-transporter in BSC-1 cells. J. Biol. Chem. 276, 42339-42346.

Weinman, E.J., Boddeti, A., Cunningham, R., Akom, M., Wang, F., Wang, Y., Liu, J., Steplock, D., Shenolikar, S., Wade, J.B., 2003(a). NHERF-1 is required for renal adaptation to a low-phosphate diet. Am. J. Physiol. 285, F1225-F1232. .

Wright. S.H., 2005. Role of organic cation transporters in the renal handling of therapeutic agents and xenobiotics. Toxicol. Appl. Pharmacol. 204, 309-319.

Yokogawa, K., Yonekawa, M., Tamai, I., Ohashi, R., Tatsumi, Y., Higashi, Y., Nomura, M., Hashimoto, N., Nikaido, H., Hayakawa, J., Nezu, J., Oku, A., Shimane, M., Miyamoto, K., Tsuji, A., 1999. Loss of wild-type 
carrier-mediated L-carnitine transport activity in hepatocytes of juvenile visceral steatosis mice. Hepatology 30, 997-1001.

Yun, C.H., Oh, S., Zizak, M., Steplock, D., Tsao, S., Tse, C.M., Weinman, E.J., Donowitz, M., 1997. cAMP-mediated inhibition of the epithelial brush border $\mathrm{Na}^{+} / \mathrm{H}^{+}$exchanger, NHE3, requires an associated regulatory protein. Proc. Natl. Acad. Sci. 94, 3010-3015.

Yun, C.C., Chen, Y., Lang, F., 2002. Glucocorticoid activation of $\mathrm{Na}^{+} / \mathrm{H}^{+}$ exchanger isoform 3 revisited. The roles of SGK1 and NHERF2. J. Biol. Chem. 277, 7676-7683. 


\section{FIGURE LEGENDS}

Fig. 1 Schematic diagram representing transporter-mediated vectorial transport of xenobiotics and nutrients in renal proximal tubules.

Fig. 2 PDZ domain-containing proteins which bind to drug transporters of the SLC superfamily

Activated ERM (ezrin-radixin-moesin) can interact with ERM binding domain (ERMB) located at the C-terminus of NHERF1 and NHERF2. ERM can also bind to protein kinase A (PKA) and $\beta$-actin.

Fig. 3 Schematic diagram representing protein-protein interactions of various types of transporters and PDZ adaptors 


\section{Xenobiotics}

\section{Nutrients}

Organic cation

Ocarnitine

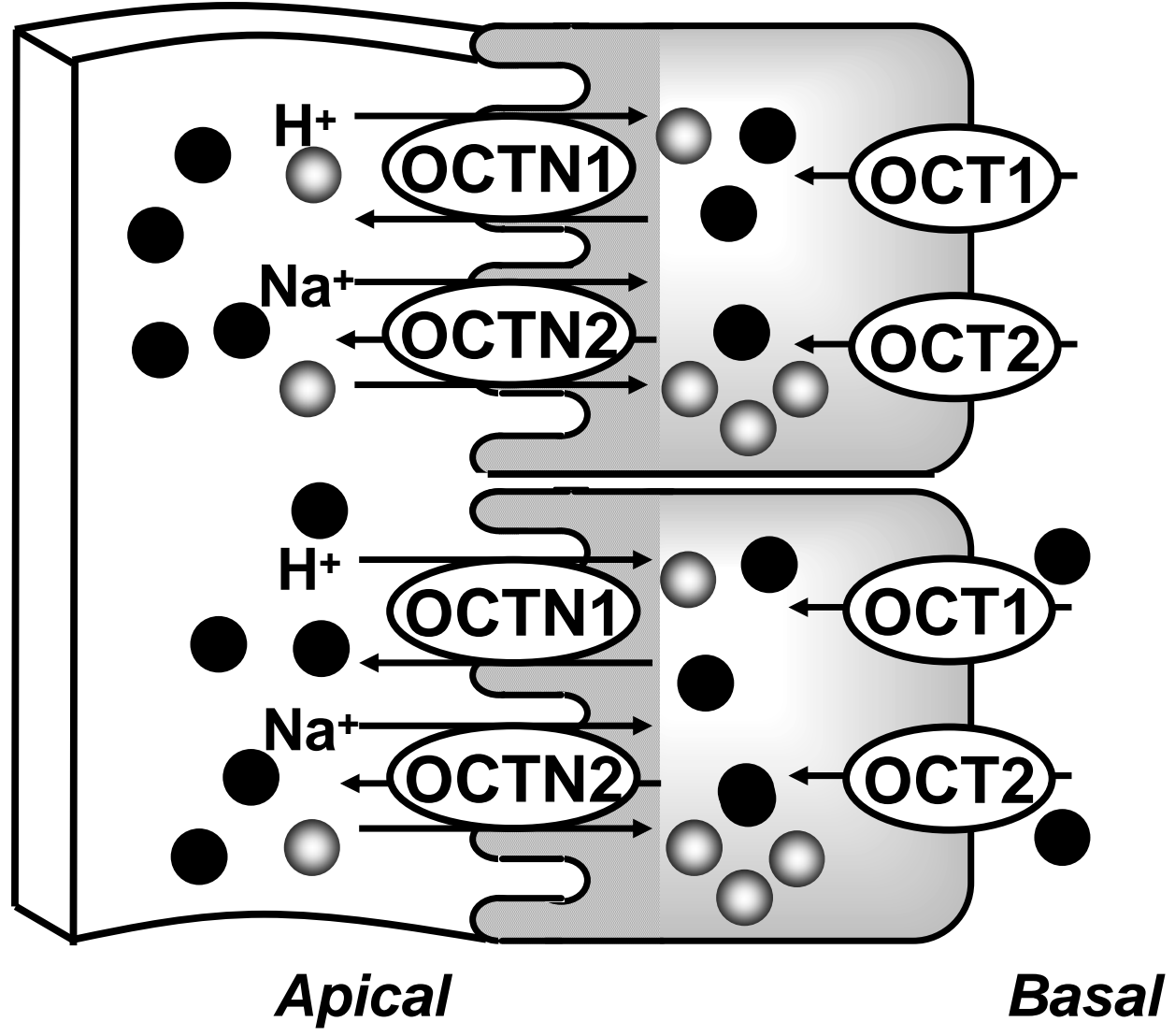

Fig. 1 
Simple Adaptors

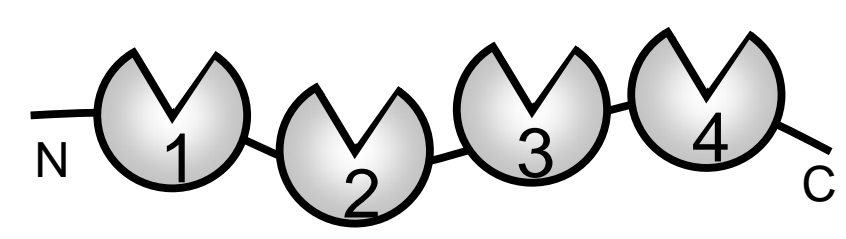

PDZK1

Complex Adaptors

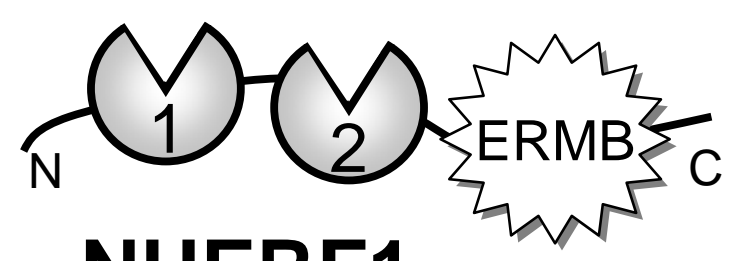

NHERF1

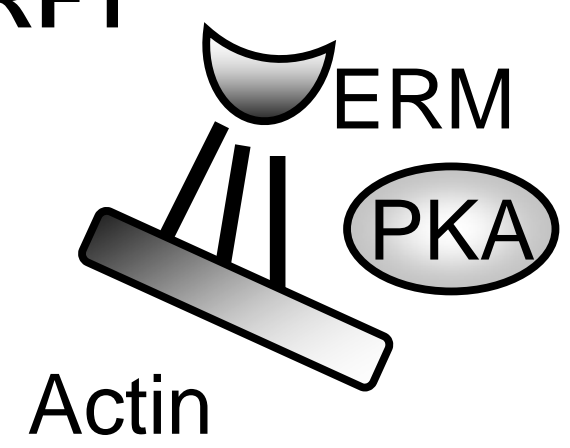

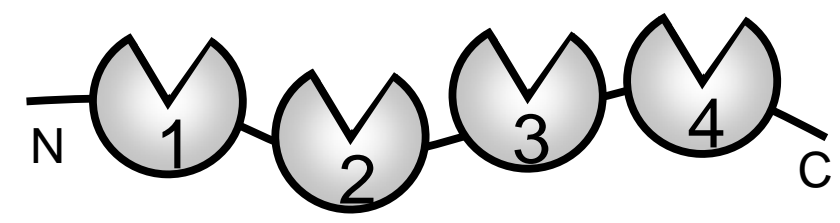

PDZK2

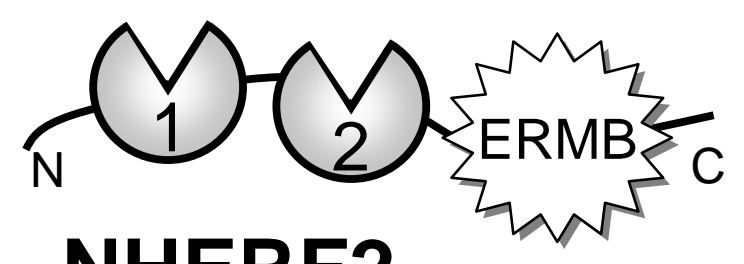

NHERF2

Actin 


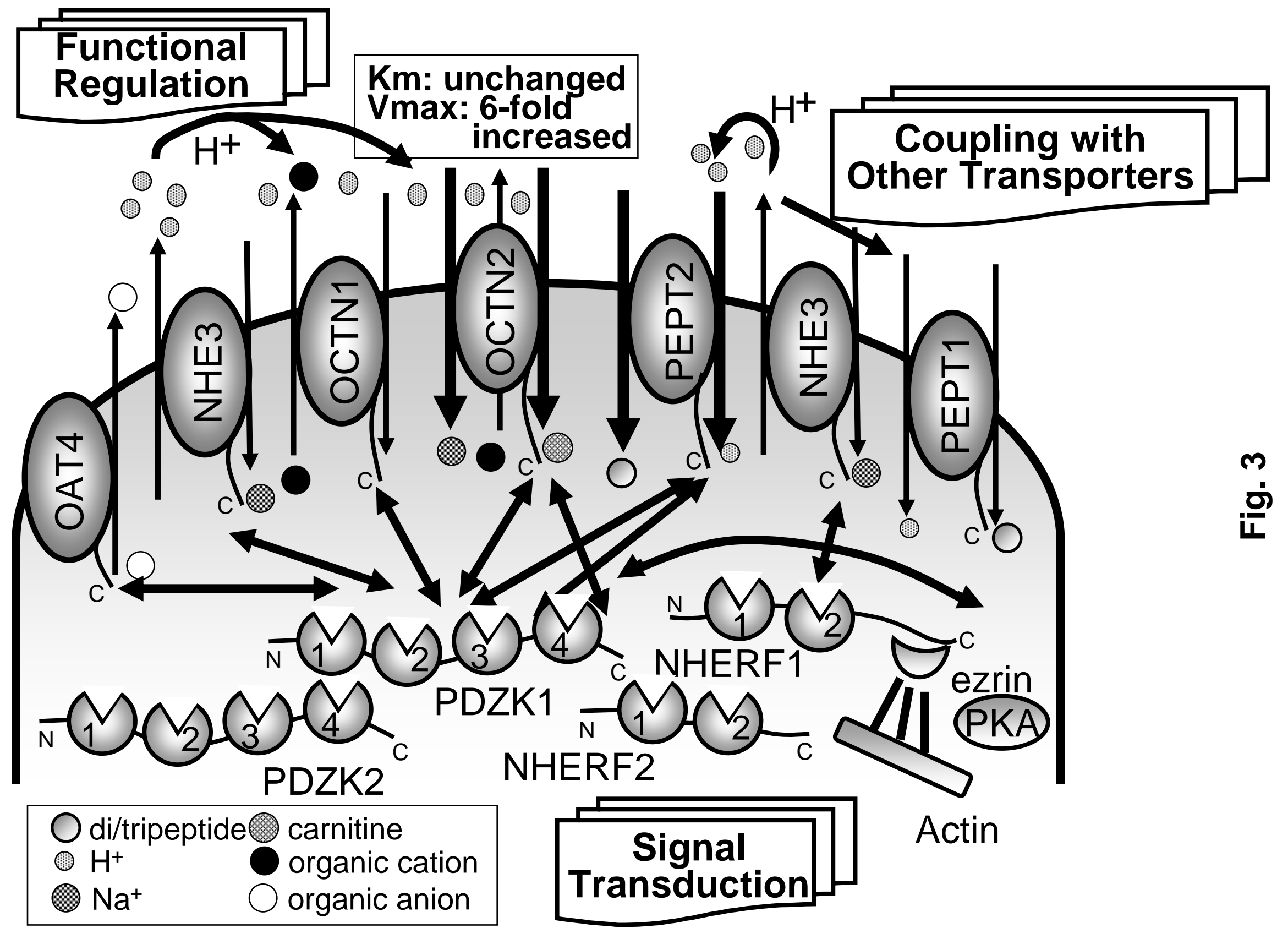


Table 1. C-terminal sequence, tissue localization and protein interaction of drug transporters of the SLC superfamily in humans and mice

\begin{tabular}{|c|c|c|c|c|c|c|c|}
\hline C-Terminusa) & \multicolumn{3}{|c|}{ Localization $\left.{ }^{b}\right)$} & \multicolumn{4}{|c|}{ Interactionc) } \\
\hline Human Mouse & Kidney & Liver & Small Intestine & PDZK1 & PDZK2 & NHERF1 & NHERF2 \\
\hline -QKQM -QTNM & Apical & Lysosome? & Apical & $(-)$ & $(+)$ & $(-)$ & $(-)$ \\
\hline -KTKL -NTRL & Apical & $(-)$ & $(-)$ & $(+)$ & $(+)$ & $(-)$ & $(-)$ \\
\hline -PSGT -SPHT & $(-)$ & Sinusoidal & $(+)$ & $(-)$ & $(-)$ & $(-)$ & $(-)$ \\
\hline -IPLN -AELS & Basolateral & $(-)$ & $(-)$ & $(-)$ & $(-)$ & $(-)$ & $(-)$ \\
\hline -RSHL -TSDV & Apical & $(+)$ & $(+)$ & $(-)$ & $(+)$ & $(-)$ & $(-)$ \\
\hline -ITAF -ПTAF & Apical & $(+)$ & $(+)$ & $(+)$ & $(+)$ & $(+)$ & $(+)$ \\
\hline -STAF -STAF & Apical & Sinusoidal & Apical & $(+)$ & $(+)$ & $(+)$ & $(+)$ \\
\hline -KNGL -KN GL & Basolateral & $(-)$ & $(-)$ & $(-)$ & $(-)$ & $(-)$ & $(-)$ \\
\hline -QVQN -TELA & Basolateral & Sinusoidal & $(-)$ & $(-)$ & $(-)$ & $(-)$ & $(-)$ \\
\hline -LGSS -TGGP & Basolateral & $(-)$ & $(-)$ & $(-)$ & $(-)$ & $(-)$ & $(-)$ \\
\hline -STSL & Apical & $(-)$ & $(-)$ & $(+)$ & $(+)$ & $(+)$ & $(+)$ \\
\hline -KTKL & $(-)$ & $(+)$ & Apical & $(+)$ & $(+)$ & $(+/-)$ & $(+/-)$ \\
\hline -DSRV & $(-)$ & Sinusoidal & Apical & $(-)$ & $(-)$ & $(-)$ & $(-)$ \\
\hline -ETHC & $(-)$ & Sinusoidal & $(-)$ & $(-)$ & $(-)$ & $(-)$ & $(-)$ \\
\hline -ESVL & $(+)$ & $(+)$ & $(+)$ & $(-)$ & $(+)$ & $(+/-)$ & $(+/-)$ \\
\hline -QSSV & $(+)$ & $(+)$ & $(+)$ & $(-)$ & $(-)$ & $(-)$ & $(-)$ \\
\hline -ETQL & $(-)$ & $(-)$ & $(-)$ & $(-)$ & $(+/-)$ & $(-)$ & $(-)$ \\
\hline$-\mathrm{AAAN}$ & $(-)$ & Sinusoidal & $(-)$ & $(-)$ & $(-)$ & $(-)$ & $(-)$ \\
\hline
\end{tabular}

a) The C-terminal sequences for human and mouse orthologs are based on NCBI reference sequences. The class I PDZ binding motif is shown in bold. The mouse ortholog for OAT4 has not been reported, and those for OATP family members are not shown due to incomplete 1:1 correspondence between human and mouse.

b) Localization observed in human and/or rodents. OAT2 is localized on basolateral and apical side of proximal tubules in human and rats, respectively. 
Table 2. Interaction of each PDZ domain in PDZK1 with Cterminal domain sequences of several membrane proteins.

\begin{tabular}{|c|c|c|c|}
\hline PDZ Domains & Proteins & Sequencesc) & References \\
\hline \multirow[t]{7}{*}{ PDZ1 } & BCR & -STEV & Malmberg et al ., 2004 \\
\hline & SR-B1a) & -EAKL & Ikemoto et al ., 2000 \\
\hline & URAT1 & -STQF & Anzai et al ., 2004 \\
\hline & MRP2 & -STKF & Kocher et al ., 1999 \\
\hline & MAP17 & -STPM & Kocher et al ., 1999 \\
\hline & NHE3 & -STHM & Gisler et al ., 2003 \\
\hline & CFTR & -DTRL & Wang et al ., 2000 \\
\hline \multirow[t]{6}{*}{ PDZ2 } & 0CTN1 & $-\mathrm{ITAF}$ & Gisler et al ., 2003 \\
\hline & OCTN2 & -STAF & Kato et al ., 2005 \\
\hline & URAT1 & -STQF & Anzai et al ., 2004 \\
\hline & РEPT2 & $-\mathrm{KTKL}$ & Kato et al ., 2004 \\
\hline & UBC9b) & -FAPS & Gisler et al ., 2003 \\
\hline & DRA & -ETKF & $\begin{array}{l}\text { Gisler et al ., 2003; Rossmann } \\
\text { et al ., } 2005\end{array}$ \\
\hline \multirow[t]{10}{*}{ PDZ3 } & NPT1 & $-\mathrm{HTRL}$ & Gisler et al ., 2003 \\
\hline & & & Custer et al ., 1997; Gisler et \\
\hline & NPT2 & -ATRL & al ., 2001, 2003 \\
\hline & PEPT2 & $-\mathrm{KTKL}$ & Kato et al ., 2004 \\
\hline & 0atp5 & $-\mathrm{KTKL}$ & Gisler et al ., 2003 \\
\hline & CFEX & $-V T R L$ & Gisler et al ., 2003 \\
\hline & & & Gisler et al ., 2003; Rossmann \\
\hline & DRA & -ETKF & et al., 2005 \\
\hline & CFTR & -DTRL & Wang et al ., 2000 \\
\hline & SLKb) & -STGS & Gisler et al ., 2003 \\
\hline \multirow[t]{9}{*}{ PDZ4 } & URAT1 & -STQF & $\begin{array}{l}\text { Gisler et al ., 2003; Anzai et } \\
\text { al ., } 2004\end{array}$ \\
\hline & 0CTN1 & $-I T A F$ & Kato et al ., 2005 \\
\hline & OCTN2 & -STAF & Kato et al ., 2005 \\
\hline & & & Kocher et al ., 1999; Gisler et \\
\hline & MAP17 & -STPM & al. , 2003 \\
\hline & NHERF1 & $-F S N L$ & Gisler et al ., 2003 \\
\hline & NHERF2 & -FSNF & Gisler et al ., 2003 \\
\hline & CFTR & -DTRL & Wang et al ., 2000 \\
\hline & D-AKAP2/AKAP10 & $-S T K L$ & Gisler et al ., 2003 \\
\hline
\end{tabular}

a) PDZ1 and approximately 40 amino acids residues following PDZ1 are necessary for the interaction.

b) These proteins were found to be expressed only in the cytosol.

c) Ihe extreme C-terminal sequences of the human orthologs of proteins interacting with PDZK1 are shown, except for the 0atp5 sequence, which is that of the mouse ortholog. 